\title{
Paratuberculosis sero- status and milk production, SCC and calving interval in Irish dairy herds
}

Hoogendam K ${ }^{1}$, Richardson $E^{2}$, Mee JF²

${ }^{1}$ LEI Wageningen UR, Agricultural Economics Research Institute, Animal Systems Division, PO Box 29703, The Hague, The Netherlands

${ }^{2}$ Teagasc, Moorepark Dairy Production Research Centre, Fermoy, Co. Cork, Ireland

\section{ABSTRACT}

The objective of this study was to investigate the impact of paratuberculosis sero-status on milk yield, fat, protein, somatic cell count and calving interval in Irish dairy herds. Serum from all animals over 12 months of age $(n=2,602)$ in 34 dairy herds was tested for antibodies to Mycobacterium avium subsp. paratuberculosis using an ELISA. Herds were categorised by sero-status into positive, non-negative and negative, where a positive herd contained two or more positive cows, a non-negative herd contained only one positive cow and a negative herd contained no positive cows. Data at animal, parity and herd-level were analysed by multiple regression using general linear models. Positive herds (mean herd size $=129$ cows) and non-negative herds ( 81 cows) were larger than negative herds $(72$ cows) $(P<0.01)$. Negative herds had the highest economic breeding index (EBI), while positive herds had the highest estimated breeding value (EBV) for milk yield. There was no significant effect of paratuberculosis sero-status at animal, parity or herd-level on milk yield, milk fat or protein production, somatic cell count score (SCCS) or calving interval. Negative herds tended to have a lower SCCS than positive and nonnegative herds $(\mathrm{P}=0.087)$. This study only examined the effects of paratuberculosis sero-status but did not examine the clinical effects of Johne's disease at the farm or dairy industry levels.

KEYWORDS: calving interval; dairy cows; ELISA; milk yield; paratuberculosis; SCC

\section{CORRESPONDING AUTHOR:}

John F Mee

Teagasc, Moorepark Dairy Production Research Centre, Fermoy, Co. Cork, Ireland.

Tel: $+353+2542387$

Fax: $+353+2542340$

E-mail: john.mee@teagasc.ie

\section{INTRODUCTION}

Paratuberculosis (Johne's disease) is a granulomatous enteritis of ruminants caused by Mycobacterium avium subspecies paratuberculosis (MAP). It is more common in cattle worldwide, particularly dairy cattle, than in other ruminants. Infected animals are generally asymptomatic until the later stages of infection when the disease manifests clinically as chronic diarrhoea and progressive emaciation. Despite an upsurge in the number of publications on paratuberculosois since 1990 (Pribylova and Hruska 2008), there are relatively few publications on paratuberculosis in Ireland. Between 1955, when Johne's disease became a notifiable disease in Ireland and 1992, when the single European market opened, Johne's disease was reported sporadically (92 cases, primarily in imported animals [1932-1992]). Following the removal of pre-importation test certification and quarantine in 1992, the number of imported cattle from the EU increased dramatically $(85,000$ cattle between 1992 and 2004). In 1997, a serological survey of 36 Irish herds with 224 imported animals found that $36 \%$ of the herds had at least one positive animal (O'Doherty et al. 2002). Between 1995 and 2002, 232 animals infected with MAP were reported in 106 Irish herds (Barrett et al. 2006). Recently, Cashman et al. (2008) analysed risk factors associated with the introduction of MAP into Irish dairy herds and concluded that there was a lack of awareness among Irish farmers about the effects of inadequate biosecurity on MAP introduction. 
The consequences of paratuberculosis for farm economics in Ireland may differ from estimates found in other countries due to the seasonal, pasture-based systems of milk production practiced here. The effect of paratuberculosis on farm production in the USA was estimated as a loss of $\$ 200$ million (Losinger 2005). Due to the potential economic consequences of the disease, several studies have attempted to estimate the impact of paratuberculosis on production, with effects on milk yield being the largest. Other variables that are considered important factors for farm economics are milk solids yield, somatic cell count (SCC), calving interval $(\mathrm{Cl})$ and early culling risk.

The effects of paratuberculosis infection on milk yield are very inconsistent, varying between increased yield in infected cows (Johnson et al. 2001), no significant effect (McNab et al. 1991) and up to a $24 \%$ reduction in yield (Barrett et al. 2006). Effects of paratuberculosis on milk solids are also inconsistent, varying between increased solids production in infected cows (Johnson et al. 2001), no significant effect (Tiwari et al. 2007) and up to a $21 \%$ reduction in solids production (Benedictus et al. 1987). In contrast to milk production, there are only a limited number of published studies on the effects of paratuberculosis on mastitis or SCC. While the majority of studies show no significant effect (Hendrick et al. 2005; Lombard et al. 2005; Gonda et al. 2007), Wilson et al. (1993) found a reduction in mastitis in subclinically infected cows and four studies showed an increase in either mastitis (Merkal et al. 1975; Buergelt and Duncan 1978) or in SCC (McNab et al. 1991; VanLeeuwen et al. 2006). The impact of paratuberculosis infection on herd fertility is similarly variable with Gonda et al. (2007) and Lombard et al. (2005) finding better fertility in infected cows; Chaffer et al. (2002) and McNab et al. (1991) finding no significant effect; and, Marce et al. (2007) and Johnson-Ifearulundu et al. (2000) finding significantly reduced fertility in infected cows. These responses vary primarily with the stage of infection, the stage of lactation, parity and the diagnostic criteria for paratuberculosis case definition (Lombard et al. 2005; Gonda et al. 2007; Raizman et al. 2007). In general, impacts on production and reproduction are much lower in subclinically infected animals (test-positive only) than in clinically affected animals.

The aim of this study was to investigate the impact of paratuberculosis sero-status on the economically important variables milk yield, milk fat and milk protein, somatic cell counts (SCC) and calving interval in dairy herds in the Republic of Ireland. The hypothesis tested was that paratuberculosis infection has a significant negative effect on milk yield, milk solids, SCC and calving interval in both infected animals and in infected herds. To address this hypothesis, the study examined the effect of paratuberculosis at the animal-level between paratuberculosis test-negative and test-positive cows, and at the herd-level between test-negative, non-negative and positive herds.

\section{MATERIALS AND METHODS \\ Data collection and editing}

The Department of Agriculture, Fisheries and Food (DAFF) conducted a national bovine paratuberculosis sero-survey in 2004 and 2005 using blood samples collected for the brucellosis eradication scheme. Samples were collected from all lactating and non-lactating animals (male and female) older then 12 months. Within this dataset, serology results from animals $(n=2,602)$ in dairy herds $(n=34)$ which were milk-recording in 2004 and 2005 were extracted. Milk and reproduction records for each paratuberculosistested cow (estimated breeding value [EBV] for milk yield, milk fat, milk protein, SCC, calving interval and economic breeding index [EBI] and predicted 305-day milk yield, milk fat, milk protein, SCC and calving interval) were retrieved from the Irish Cattle Breeding Federation (ICBF) database and matched to the test results from DAFF by animal tag number. When matching the DAFF database with the IBCF database, there were two herds ( $n=80$ animals) with no milk records available, so these were removed from the entire analysis. Of the 2,522 animals in the remaining 32 herds, 355 animals in the ICBF database did not have milk records (males) or matching tag numbers, and so were removed. When matching serology test data to production data for the lactation during the year of the paratuberculosis test (current lactation) a further 1,150 cow records were lost, as they were either not lactating in the test year, or no data were available for that animal in that year. As days in milk (DIM) influences the estimations of total milk yield, test day recordings before 100 DIM and after 450 DIM were excluded from the analysis, by taking the $95 \%$ confidence interval around the mean for DIM (264 days). Calving intervals ranging between 300 and 500 days were retained for analysis. After further checking for errors and outliers, data was available for 993 lactating cows in 32 herds. The dataset was comprised of $95.6 \%$ HolsteinFriesian cows. Therefore, to remove the effect of breed on production and reproduction variables, all other breeds were deleted leaving 949 cows in 32 herds. The EBV of the cow (not the sire) was recorded for 259 of the 949 cows.

\section{Serology}

Paratuberculosis status was established using an ELISA (Elisa Bovine Paratuberculosis Serum Verification, Institut Pourquier, France) with a specificity of $99.8 \%(\mathrm{Cl} 95 \%$ 99.6-99.8) and a sensitivity of 40.8\% (CI 95\% 35.3-46.7), (Maanen van et al. 1999) in a DAFF laboratory. A sample to positive (S/P) ratio of $\geq 70 \%$ was considered positive. All samples with an S/P ratio below this cut off value were defined as negative.

\section{Animal-level}

A case-control study design was used to match each paratuberculosis test-positive cow (case) with five negative cows (1:M) (controls) all of which had data available for their current lactation. This ratio was calculated using the general linear model (GLM) procedure, with 
paratuberculosis status as a fixed factor and match number (the number of the matched pairs, one to 11) as a random factor. The cows were paired on parity and calving date, where the calvings of the controls were within one month of the cases. The GLM procedure (univariate) was used to examine the effect of paratuberculosis sero-status on milk yield, fat, protein, SCC and previous calving interval in negative and positive cows.

\section{Herd-level}

The herds were categorised into three groups: test-negative, non-negative and positive. To exclude the risk of a false positive herd in the analysis, the restrictive definition for classifying herds used by VanLeeuwen et al. (2005) and Sorensen et al. (2003), where a herd has to contain two or more positive animals before it is classified as a positive herd, was used. A herd was classified as a negative herd if all the animals in the herd had negative test results. A herd with only one animal that tested positive for paratuberculosis was categorised as non-negative, as it is not possible to clearly define these herds as either positive or negative.

Preliminary analyses were done on the data to verify that the assumptions of parametric data were not violated. The Levene's test of equality of error variances and the Kolmogorov-Smirnov tests were used to test for the homogeneity of variance and normality, respectively. After converting SCC to somatic cell count score (SCCS) (Smith et al. 2002) as shown in Table 1 and converting lactation length into a logarithmic variable, all variables met the required assumptions. The variable parity was divided into four groups $(1,2,3$ and $\geq 4)$. Herd size (number of animals over 12 months) was divided in three groups (small 1-50, medium 51-100 and large $\geq 101$ ). A multiple linear regression analysis was initially used to determine the association between herd paratuberculosis status (negative, positive, non-negative), herd identifier number (number of the herd of the cow), herd size, parity, month of calving and lactation length (days in milk) and the dependent variables (milk yield, milk fat, milk protein, SCCS and calving interval). In this initial exploratory data analysis, unadjusted for EBV, the positive and larger herds had a higher milk yield, fat and protein production than the negative herds. However, given the differences in EBV between herd paratuberculosis categories and the likely impact of EBVs on the dependent variables and model fit, EBVs were included in subsequent models as covariates. Univariate general linear models were used for each dependent variable, with herd paratuberculosis status, herd size and parity as fixed factors and lactation length (in logarithmic form) and the EBVs of the dependent variables as covariates. Milk yield was included as a covariate to analyse effects on protein and fat production, because they are linked to milk yield. An adjustment was made in the models for a significant interaction between herd paratuberculosis status and herd size. Each model structure used was:

Equation 1: $Y=X_{0}+\sum\left(B_{1} X_{i}\right)+E_{i}$
Where $Y$ is the corrected total effect of the explanatory variables on the dependent variable (the model was run for each dependent variable) $X_{0}$ is the intercept or mean of the model. $\mathrm{B}_{1} \mathrm{X}_{\mathrm{i}}=$ independent variables: herd paratuberculosis status, herd size, parity, lactation length (log) and EBV of the dependent variable. $E_{i}$ is the random error term. A pairwise comparison between herd paratuberculosis statuses was carried out using the Bonferroni adjustment for multiple comparisons post hoc analysis. The calculated implied power of these statistical models where one is the highest power and zero the lowest, were all above the cut off value of 0.80 (Field 2004).

\section{Table 1: Somatic cell count scores (SCCS) and associated ranges in somatic cell counts (SCC) (cells/ml) (Smith et al. 2002)}

\begin{tabular}{|l|l|}
\hline Somatic cell count score (SCCS) & Somatic cell count (SCC) (cells/mI) \\
\hline 0 & $0-18,999$ \\
\hline 1 & $19,000-35,999$ \\
\hline 2 & $36,000-71,999$ \\
\hline 3 & $72,000-141,999$ \\
\hline 4 & $142,000-283,999$ \\
\hline 5 & $284,000-565,000$ \\
\hline
\end{tabular}

To determine the effect of paratuberculosis within different parity groups, a general linear model was run separately for each parity group. The analysis contained the same herds and number of cows as used on the herd-level, but the cows were split up into the four parity groups $(1,2,3$ and $\geq 4$ ). The model for each dependent variable in each parity group contained herd paratuberculosis status and herd size as fixed effects, lactation length (in log format) and the EBVs of the dependent variables as a covariate and the interaction between herd paratuberculosis status and herd size as an interaction term. The pair-wise comparisons were carried out using the Bonferroni post hoc analysis. Results were considered significant at a P-value of $\leq 0.05$. The statistical analyses were conducted using SPSS version 14.0.1 (2006).

\section{RESULTS}

\section{Paratuberculosis sero-status}

Of the 949 cows in the final dataset, there were 13 cows that were paratuberculosis sero-positive with OD values ranging from 84 to 241 . Of the 32 herds (949 cows) tested, there were eight positive, eight non-negative and 16 negative herds. The positive herds (mean herd size $=129$ cows) and the non-negative herds (81 cows) were larger than the negative herds (72 cows) $(\mathrm{P}<0.01)$.

\section{Animal-level effects}

Eleven sero-positive cows could be matched with 55 seronegative cows for milk yield, protein, fat and SCCS. The mean (range) age, milk yield, SCC and lactation length of the sero-positive cows was 50 months (28-73), 6,292 kg (3,810-8,795), 169,083 cells/ml (44,000-1,090,000) and 
250 days (175-304), respectively. Two of the 11 positive cows were in first parity; therefore for calving interval [mean (range) 371 days (335-424)] only nine positive cows could be matched with 45 negative cows. At the animal-level, paratuberculosis sero-status had no effect on any of these dependent variables $(P>0.05)$.

\section{Herd-level effects}

Table 2 shows the outputs from the multiple regression models comparing positive, negative and non-negative herds using the restricted dataset with EBV records.

Overall, herd paratuberculosis sero-status had no significant effect on milk yield, milk fat or milk protein production or on calving interval. Negative herds tended to have a lower SCCS than the positive and the non-negative herds $(P=0.087)$. The positive herds had a significantly higher EBV for milk yield, SCC and calving interval than the negative herds (Figure 1, 2, 3). However, the negative herds

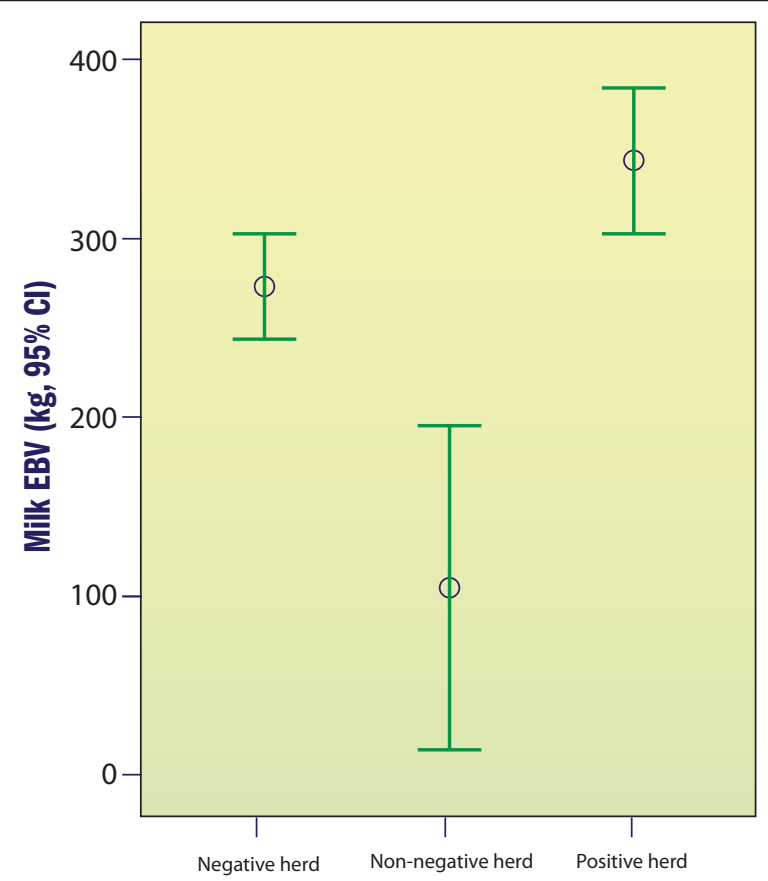

\section{Herd status}

Figure 1: The Economic Breeding Value (EBV) for milk yield (kg) of paratuberculosis positive, non-negative or negative herds. had a significantly higher EBV for EBI than the positive herds (Figure 4). EBVs for milk fat and protein did not differ between negative and positive herds. Non-negative herds had significantly lower EBVs for milk yield, protein, calving interval and EBI than negative or positive herds but did not differ for SCC and fat.

\section{Parity-level effects}

When the data were examined at parity-level, there were no significant differences between positive, non-negative and negative herds in the four parity groups for milk yield, milk fat, milk protein, SCC or calving interval. However, cows in parity 3 in positive herds tended to have a higher average milk yield than those in parity 3 in negative herds [7636.46 kg (6878-8395) vs. 6590.82 kg (6075-7107), $P=0.079]$. Cows in parity group 4 in positive herds tended to have a higher SCCS than cows in parity group 4 in negative herds [4.13 (2.6-5.6) vs. 2.84 (1.9-3.8), $\mathrm{P}=0.087$ ].

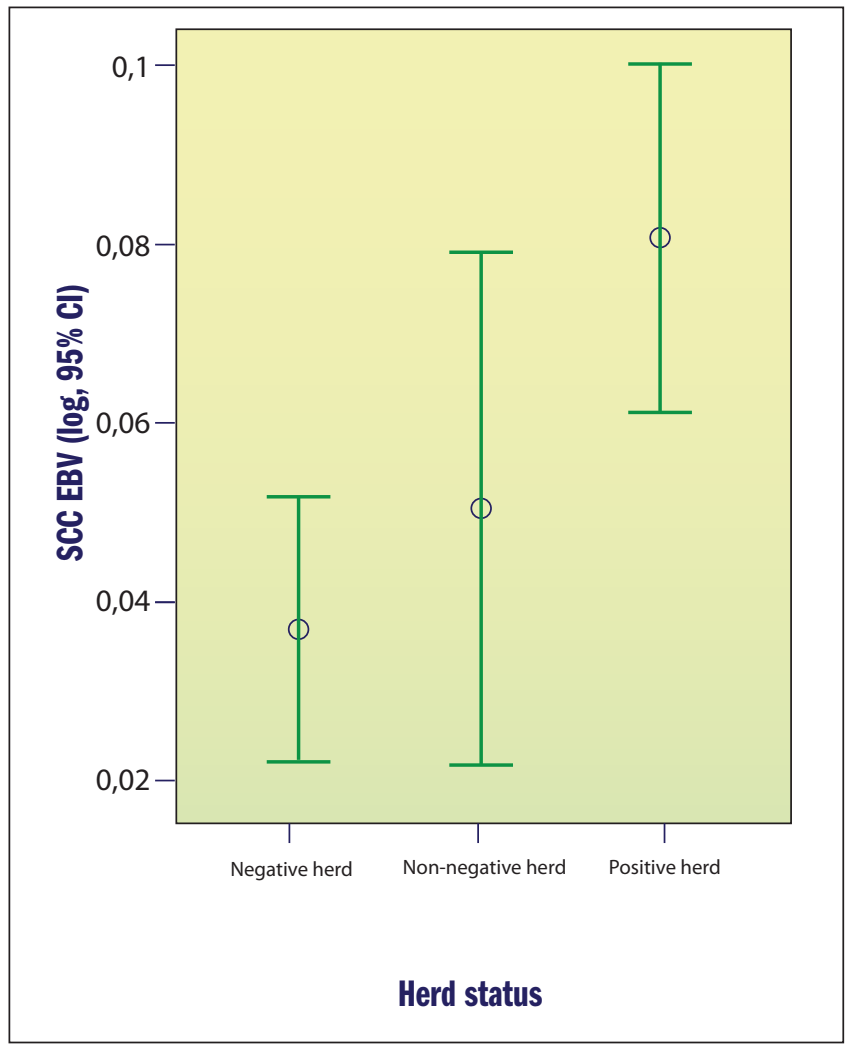

Figure 2: The Economic Breeding Value (EBV) for somatic cell count (SCC) of paratuberculosis positive, non-negative or negative herds.

Table 2: The effect of herd paratuberculosis sero-status (positive, negative or non-negative) on milk, fat and protein yield, somatic cell count score (SCCS) and calving interval [mean $(95 \% \mathrm{Cl})]$

\begin{tabular}{|l|l|l|l|l|l|l|}
\hline Variables & Positive & Non-negative & Negative & F-value & Adjusted R & P-value \\
\hline Milk $(\mathrm{kg})$ & $6981.44(6594-7369)$ & $6928.00(6594-7369)$ & $6601.85(6408-6795)$ & 1.995 & 0.447 & 0.138 \\
\hline Fat $(\mathrm{kg})$ & $242.20(231-253)$ & $238.50(226-251)$ & $238.03(232-244)$ & 0.213 & 0.7 & 0.809 \\
\hline Protein $(\mathrm{kg})$ & $222.09(216-228)$ & $220.79(214-228)$ & $215.75(213-219)$ & 2.031 & 0.871 & 0.133 \\
\hline SCCS (score) & $3.26(2.7-3.8)$ & $3.38(2.7-4.0)$ & $2.76(2.5-3.0)$ & 2.469 & 0.021 & 0.087 \\
\hline Calving interval (day) & $386.42(368-405)$ & $391.63(364-419)$ & $381.67(372-391)$ & 0.696 & 0.063 & 0.5
\end{tabular}




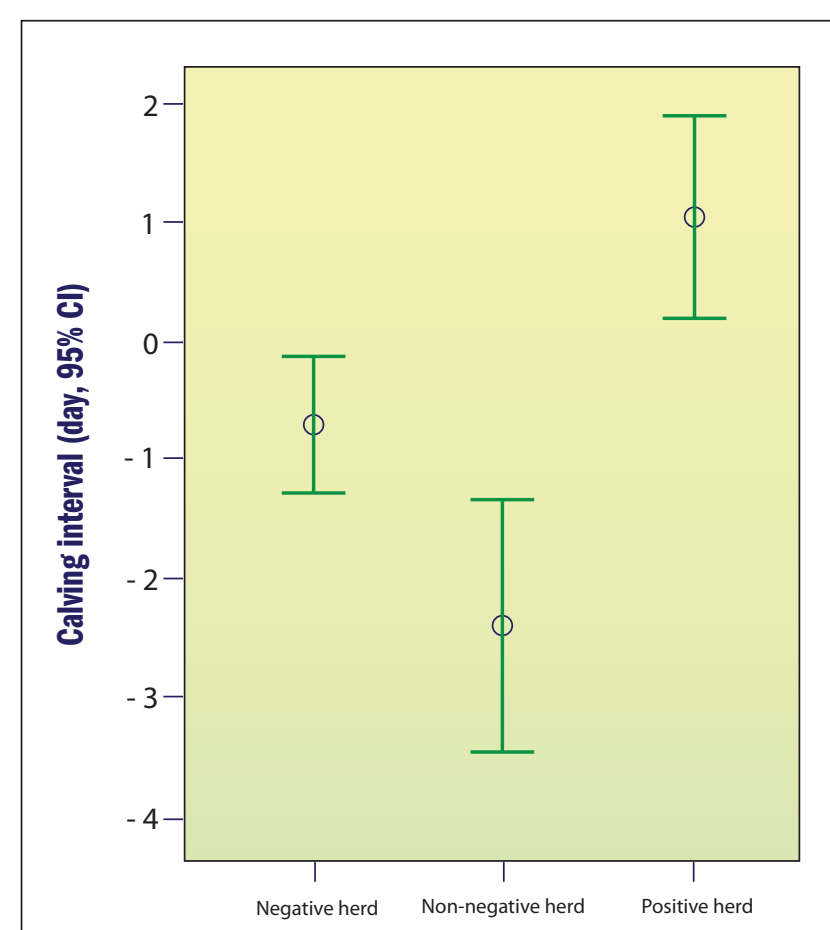

Herd status

Figure 3: The Economic Breeding Value (EBV) for calving interval (days) of paratuberculosis positive, non-negative or negative herds.

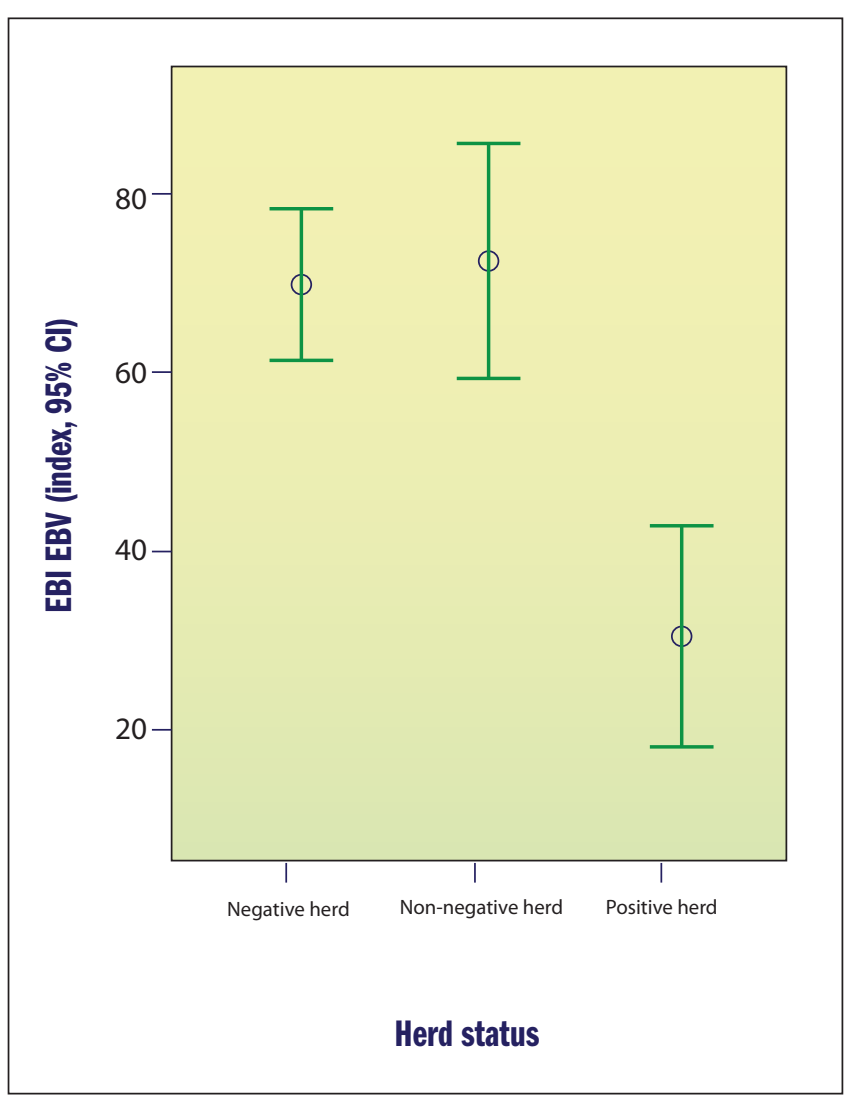

Figure 4: The Economic Breeding Value (EBV) of the Economic Breeding Index (EBI) of paratuberculosis positive, non-negative or negative herds.

\section{DISCUSSION}

The hypothesis that there would be a reduction in production and reproductive performance between paratuberculosis-positive and negative herds was rejected. This study showed no significant effect of herd paratuberculosis sero-status on milk yield, fat, protein, SCCS and calving interval. The fit of the general linear models was good for milk yield $\left(R^{2}=0.45\right)$, and fat and protein yield ( $\left.R^{2} \geq 0.70\right)$, but poorer for SCCS and calving interval $\left(R^{2}<0.10\right)$. Though the SCCS was numerically higher for positive and non-negative herds than for negative herds, all of the herd SCCS scores indicated mean herd SCC of between the 36 and 283,000 cells per ml. Recently, Dieguez et al. (2008) found that seropositivity to MAP was related to bulk tank SCC and the incidence of mastitis. While clinical paratuberculosis has been shown to have significant negative economic impacts in both pasture-based (Barrett et al. 2006) and confinement systems (Benedictus et al. 1987), the impact of subclinical paratuberculosis (test-positive only) is less clear. For example, in the UK, with management systems not greatly dissimilar from those in Ireland, Stott et al. (2005) found that the financial effect of paratuberculosis is considerably lower than for other major endemic diseases of dairy cows. Dufour et al. (2004) stated that the calculation of losses caused by paratuberculosis is affected by the production system of a herd, its size, production level, herd management (especially rearing of calves and young animals) and other factors.

In the present study, the large positive herds had a significantly higher EBV for milk, while the smaller negative herds had a higher overall EBV, and when adjusting for EBV, the difference in milk yield was no longer significant. It might be the case that the selection for high milk yield in the positive herds made the cows more vulnerable to infection with paratuberculosis. There is a general consensus that when selecting for a higher milk yield, the genetic merit for health decreases (Pryce et al. 1998; Jakobsen et al. 2003;). Koets et al. (2000) provided evidence for the presence of genetic variation in the susceptibility of cattle to paratuberculosis. The average milk production in the non-negative and positive herds was higher than the average milk production $(6,677 \mathrm{~kg} / \mathrm{cow})$ of Irish milk-recorded herds. The fat and protein production was similar to that of Irish milk-recorded herds (244 kg fat and $221 \mathrm{~kg}$ protein). There is another possible reason for the relationship found between larger herds, the number of positive cows and high EBV milk yield. It is proposed that farmers with large herds may have imported cows with high genetic merit for milk yield from abroad and inadvertently imported MAP carriers, as genetics at the time were mainly sourced from countries where paratuberculosis is now recognised. The non-negative and negative herd had higher EBV-EBI values than the positive herds, but lower EBI-milk. This also suggests that these herds may not have selected as strongly for EBV-milk, as they had higher EBV-SCC and EBV-Cl cows which would have contributed to a higher EBV$\mathrm{EBI}$ found in these herds. 
The results for herd-level analysis are consistent with those for the parity and animal-levels. The outcome of the case-control study showed that there was no difference in the five production parameters between test-positive and test-negative cows. This is in agreement with Johnson et al. (2001) who found no difference in milk, fat or protein production in 533 cows from seven herds with an animallevel MAP prevalence of 59.9\%. However, it should not be concluded that paratuberculosis is an economically unimportant disease in the Irish dairy industry. On a very small number of Irish farms there have been major outbreaks of Johne's disease (Barrett et al. 2006) which caused huge financial loss. At the Irish dairy industry level, paratuberculosis presents a continual threat to our export of dairy products given the uncertainty regarding the link with Crohn's disease and the progress on national control programmes internationally. In addition, while this study examined the effects of paratuberculosis sero-status it could not address the impacts of clinical Johne's disease on veterinary costs, culling rates and animal welfare.

\section{ACKNOWLEDGEMENTS}

The authors thank the staff in DAFF and in ICBF for access to records on paratuberculosis sero-status and milk production and calving interval, respectively.

\section{REFERENCES}

Barrett D, Good M, Hayes M et al. (2006) The economic impact of Johne's disease in an Irish dairy herd: a case study. Irish Veterinary Journal 59, 301-305.

Benedictus G, Dijkhuizen AA and Stelwagen J (1987) Economic losses due to paratuberculosis in dairy cattle. Veterinary Record 121, 142-146.

Buergelt CD, Duncan JR (1978) Age and milk production data of cattle culled from a dairy herd with paratuberculosis. Journal of the American Veterinary Medical Association 173, 478-480.

Cashman W, Buckley J, Quigley T et al. (2008) Risk factors for the introduction and within-herd transmission of Mycobacterium avium subspecies paratuberculosis (MAP) infection on 59 Irish dairy herds. Irish Veterinary Journal, 61. 464-467.

Chaffer M, Grinberg K, Ezra E et al. (2002) The effect of sub-clinical Johne's disease on milk production, fertility and milk quality in Israel. In: Proceedings of the Seventh International Colloquium on Paratuberculosis, Bilbao, Spain. Pp 351-352.

Dieguez FJ, Arnaiz I, Sanjuan ML et al. (2008) Management practices associated with Mycobacterium avium subspecies paratuberculosis infection and the effects of the infection on dairy herds. Veterinary Record 162, 614-617.

Dufour B, Pouillot R and Durand B (2004) A cost/benefit study of paratuberculosis certification in French cattle herds. Veterinary Research 35, 69-81.

Field AP (2004) Discovering Statistics Using SPSS. Second edn. Sage, London. P 779.

Gonda MG, Chang YM, Shook GE et al. (2007) Effect of Mycobacterium paratuberculosis infection on production, reproduction, and health traits in US Holsteins. Preventive Veterinary Medicine 80, 103-119.

Hendrick SH, Kelton DF, Leslie KE et al. (2005) Effect of paratuberculosis on culling, milk production, and milk quality in dairy herds. Journal of the American Veterinary Medical Association 227, 1302-1308.

Jakobsen JH, Rekaya R, Jensen J et al. (2003) Bayesian estimates of covariance components between lactation curve parameters and disease liability in Danish Holstein cows. Journal of Dairy Science 86, 30003007

Johnson YJ, Kaneene JB, Gardiner JC (2001) The effect of subclinical Mycobacterium paratuberculosis infection on milk production in Michigan dairy cows. Journal of Dairy Science 84, 2188-2194.

Johnson-Ifearulundu YJ, Kaneene JB, Sprecher DJ et al. (2000) The effect of subclinical Mycobacterium paratuberculosis infection on days open in Michigan, USA, dairy cows. Preventive Veterinary Medicine 46, 171-181.

Koets AP, Adugna G, Janss LLG et al. (2000) Genetic variation of susceptibility to Mycobacterium avium subsp. paratuberculosis infection in dairy cattle. Journal of Dairy Science 83, 2702-2708.

Lombard JE, Garry FB, McCluskey BJ et al. (2005) Risk of removal and effects on milk production associated with paratuberculosis status in dairy cows. Journal of the American Veterinary Medical Association 227, 19751981.

Losinger WC (2005) Economic impact of reduced milk production associated with Johne's disease on dairy operations in the USA. Journal of Dairy Research 72, 425-432.

Maanen van K, Koster C and Veen van B (1999) Validation report: Mycobacterium paratuberculosis antibody detecting ELISAs (Deventer, Animal Health Service). Pp 1-24.

Marce C, Beaudeau F, Bareille N et al. (2007) Effects of infection by Mycobacterium avium paratuberculosis on fertility of dairy cows. Proceedings of the $9^{\text {th }}$ International Colloquium on Paratuberculosis, Tsukuba, Japan. Pp 114-115.

McNab WB, Meek AH, Martin WS et al. (1991)

Association between dairy production indices and lipoarabinomannan enzyme-immunoassay results for paratuberculosis. Canadian Veterinary Journal 55, 356361.

Merkal RS, Larsen AB and Booth GD (1975) Analysis of the effects of inapparent bovine paratuberculosis. American Journal of Veterinary Research 36, 837-838.

O'Doherty A, O'Grady D, O'Farrell K et al. (2002) Survey of Johne's disease in imported animals in the Republic of Ireland. Veterinary Record 150, 634-636.

Pribylova R, Hruska K (2008) Publications on paratuberculosis in 2005-2007. The Paratuberculosis Newsletter March. Pp 13-21.

Pryce JE, Esslemont RJ, Thompson R et al. (1998) 
Estimation of genetic parameters using health, fertility and production data from a management recording system for dairy cattle. Animal Science 66, 577-584.

Raizman EA, Fetrow J, Wells SJ et al. (2007) The association between Mycobacterium avium subsp. paratuberculosis faecal shedding or clinical Johne's disease and lactation performance on two Minnesota, USA dairy farms. Preventive Veterinary Medicine 78, 179-195.

Smith JW, Chapa AM, Gilson WD et al. (2002) Somatic cell counts benchmarks. Cooperative Extension Service, The University of Georgia College of Agricultural and Environmental Sciences. Pp 1-30.

Sorensen O, Rawluk S, Wu J et al. (2003) Mycobacterium paratuberculosis in dairy herds in Alberta. Canadian Veterinary Journal 44, 221-226.

SPSS (2006) SPSS 14.0.1 for Windows Patch (Chicago, SPSS inc.).

Stott AW, Jones GM, Humphry RW et al. (2005) Financial incentive to control paratuberculosis on dairy farms in the United Kingdom. Veterinary Record 156, 825-31.

Tiwari A, VanLeeuwen JA, Dohoo IR et al. (2007) Production effects of pathogens causing bovine leukosis, bovine viral diarrhea, paratuberculosis, and neosporosis. Journal of Dairy Science 90, 659-669.

VanLeeuwen JA, Forsythe L, Tiwari A et al. (2005) Seroprevalence of antibodies against bovine leukemia virus, bovine viral diarrhea virus, Mycobacterium avium subspecies paratuberculosis, and Neospora caninum in dairy cattle in Saskatchewan. Canadian Veterinary Journal 46, 56-58.

VanLeeuwen J, Tiwari A, Dohoo I et al. (2006) Effects of bovine leukosis virus, bovine viral diarrhea virus, Mycobacterium paratuberculosis, and Neospora caninum on somatic cell count. Proceedings of the 11th Conference of the International Society of Veterinary Epidemiology and Economics, Cairns, Australia. P 250.

Wilson DJ, Rossiter C, Han HR et al. (1993) Association of Mycobacterium paratuberculosis infection with reduced mastitis, but with decreased milk production and increased cull rates in clinically normal dairy cows. American Journal of Veterinary Research 54, 1851-1857. 